\title{
Improving Hepatocellular Carcinoma (HCC) Detectability Using Cone Beam CT (CBCT) During Transarterial Chemo-Embolization (TACE)
}

\author{
AHMED H. SOLIMAN, M.D.; MARWA E. IBRAHIM, M.D. and ALIAA S. SHEHA, M.D. \\ The Department of Radiodiagnosis, Faculty of Medicine, Ain Shams University
}

\begin{abstract}
Background: Trans-catheter arterial chemoembolization is one of the effective therapeutic options for hepatocellular carcinoma (HCC). Ultra-selective chemoembolization is an approach improving the local control, and is associated with a reduced incidence of adverse effects.

Aim of Study: It was to evaluate the sensitivity of cone beam computed tomography (CBCT) in detecting HCC tumors and their feeding vessels during trans-arterial chemoembolization (TACE).

Patients and Methods: All patients were suspected of having or confirmed to have HCC based on clinical history, underlying liver disease and/or viral infection, the diagnosis of HCC was made by imaging findings. Between January 2018 and January 2019, the prototype chemoembolization guidance software for syngo Dyna CT was retrospectively used in 25 consecutive patients with HCC tumor.
\end{abstract}

Results: The detectability of the tumor with non-selective DSA obtained at the common, proper, right, or left hepatic arteries and compared to cone-beam CT. The tumor stain and feeding branches were evaluated. Detectability of the tumorfeeding branch with non-selective DSA and Dyna CT analyzing the first CT HA images was compared. Tumor detectability on cone-beam CT was significantly greater than on nonselective. Cone beam HA could depict $(91.5 \%)$ of tumors. Nonselective DSA could depict only $(72.1 \%)$. Cone-beam CT has satisfactory ability to detect tumors; could identify $81 \%$ of tumor-feeding branches at the level of the sub- sub segmental artery of the hepatic artery in HCC lesions.

Conclusion: The technical success rates of ultraselective transcatheter arterial chemoembolization may be improved by chemoembolization guidance software that uses cone-beam CT technology.

Key Words: Cone beam computed tomography - Hepatocellular carcinoma - Transarterial chemoembolization.

Correspondence to: Dr. Ahmed H. Soliman, The Department of Radiodiagnosis, Faculty of Medicine, Ain Shams University

\section{Introduction}

TRANSARTERIAL chemoembolization (TACE) is a recommended therapeutic option for many patients with inoperable $\mathrm{HCC}$, this malignant neoplasm is having unique characteristics on crosssectional multiphase contrast CT or MR imaging allowing for a highly accurate diagnosis of HCC without an invasive biopsy. The diagnosis is based on the qualitative or visual appreciation of differences in attenuation on CT and signal intensities on MRI of the HCC with respect to surrounding liver parenchyma [1].

Typical HCC demonstrates arterial enhancement followed by washout at computed tomography (CT) [2] . By magnetic resonance (MR) imaging HCC usually appears as a hypo intense nodule at T1-WI comparing to the surrounding parenchyma, On T2-WI it shows a mild hyper intense signal in post contrast imaging, enhancement is usually arterial with rapid "washout", becoming hypo intense to the remainder of the liver with restricted diffusion [3].

One of the most common reasons for early recurrence after treatment is the inability to identify all lesions including the small or occult tumors prior to treatment. Therefore, detection of all tumor nodules, including the smaller HCCs $(<3 \mathrm{~cm})$, is essential in achieving best treatment results [4] .

Unfortunately, angiography frequently cannot detect small HCC lesions. In addition, conventional triphasic contrast enhanced $\mathrm{CT}$ and magnetic resonance imaging (MRI) are less sensitive in detecting small lesions [4]. 
Another area of controversy is the optimal management of patients in whom CT or MRI detects a nodule with some but not all the hallmark features of HCC. The differential diagnosis for such nodules includes HCC, non-HCC malignancy, and non-malignant entities [5]

Cone-beam CT is a dynamic examination which gives an intra-operative 3D CT-like imaging in the cath-lab without moving the catheterized patient or the table [6]. It provides computed tomographic (CT) images from a rotational scan acquired with a C-arm equipped with a flat panel detector. Using CBCT while performing interventional procedures can cross the bridges between the 3D diagnostic imaging world and the 2D interventional radiology world. Therefore, cone-beam CT can improve the feasibility, effectiveness and the safety of many image guided procedures [7].

\section{Aim of the study:}

The objective of this study is to evaluate the sensitivity of CBCT in detecting HCC tumors and their feeding vessels during TACE.

\section{Patients and Methods}

Between January 2018 and January 2019, the prototype chemoembolization guidance software for Syngo Dyna CT was prospectively used in 25 consecutive patients referred to our interventional radiology unit in Ain Shams University Hospitals with HCC tumors. The study was approved by the ethics committee and the institutional review board after obtaining oral and written consents from our patients.

The present study was designed to evaluate the detectability of tumor and tumor feeding branches in HCC lesions with the use of chemoembolization guidance software compared with DSA and preprocedural imaging (CT and MRI).

Prototype software that assists in the identification of the tumor-feeding branch with the use of cone-beam CT data (floor mounted artis zee; Siemens Medical Systems) was made available by the manufacturer. Our institutional review board approved the use of a prototype of the chemoembolization guidance software and the performance of the present study.

\section{Patients:}

All patients were suspected of having or confirmed to have $\mathrm{HCC}$ on the basis of clinical history, underlying liver disease and/or viral infection, the diagnosis of HCC was made by imaging findings.
Our imaging criteria for the diagnosis of HCC were as follows: (i) Nodular staining and washout on dynamic $\mathrm{CT}$ and/or dynamic magnetic resonance (MR) imaging. (ii) Nodular staining on angiography and/or CT during hepatic arteriography (HA and, in addition to dense nodular accumulation of iodized oil (Lipiodol) on cone-beam CT.

\section{Inclusion criteria:}

- Initial presentation of $\mathrm{HCC}$ without previous treatments.

- Hyper vascular nodules satisfying the imaging diagnosis criteria of HCC.

- According to Barcelona clinic liver cancer (BCLC):

Stage A (performance status "PS" 0-2, ChildPugh A to C, solitary lesion $>2 \mathrm{~cm}$ or early multifocal disease characterized by up to 3 lesions measuring less than $3 \mathrm{~cm}$.).

Stage B (performance status "PS" 0, ChildPugh A to C, multifocal disease: more than one lesion with at least one over $3 \mathrm{~cm}$, or more than 3 lesions regardless their size).

The imaging criteria for the diagnosis of HCC according to EASL "European Association for the Study of the Liver" and AASLD "American association for the Study of Liver disease" Criteria for the radiologic diagnosis of hepatocellular carcinoma can be made at either CT or MR imaging, provided that a multiphasic contrast material-enhanced study is used. If the lesion demonstrates characteristic features of hepatocellular carcinoma that is, arterial phase hyper enhancement and portal venous or delayed phase washout-with a single modality, the diagnosis can be made and no further investigation is required $[8]$

\section{Exclusion criteria:}

- Diffuse infiltrative HCC.

- Malignant portal vein thrombosis.

- Patient with decompensated cirrhosis (ChildPugh B, score >8), including jaundice, clinical hepatic encephalopathy, and refractory ascites and/hepatorenal syndrome.

- Contraindication to contrast medium (Impaired renal function Creatinine $\geq 1.5 \mathrm{mg} / \mathrm{dl}$ or creatinine clearance $<30 \mathrm{ml} / \mathrm{min}$ ).

\section{Data collection and preparation of the patient's:}

All procedures were done by an experienced team, with local anesthesia and standardized techniques using Siemens artis zee interventional angiography system with Dyna CT device. 
All cases were subjected to: Thorough detailed history taking, Meticulous clinical examination, Laboratory investigations including: Complete blood picture, liver function tests, kidney function tests and coagulation profile (PT, PC and INR), Triphasic CT or dynamic MRI was done in all cases. Routine preparation before the procedure was fasting for 6 hours before the procedures, and control blood pressure and blood sugar.

Angiography protocol: Two-dimensional DSA of the common hepatic or proper hepatic artery was achieved with a5-F catheter with injection of $12 \mathrm{~mL}$ of contrast material at a rate of $3 \mathrm{~mL} / \mathrm{s}$. DSA of the selected branches was also obtained with manual injection of $2.5 \mathrm{~mL}$ of contrast material through a microcatheter [7].

\section{CBCT technique:}

An angiographic unit with a flat panel detector to obtain CBCT images: In our CBCT protocol (Artis zee floor mounted system with Dyna CT; Siemens, Forchheim,Germany), 321 projection images with X-ray parameters of $51-120 \mathrm{kV}$ and 101-125mA are obtained by 10.4-s acquisition with $207^{\circ}$ rotation of a $30 \times 38 \mathrm{~cm}$ FPD of the angiographic $\mathrm{C}$-arm around the patient. $\mathrm{CBCT}$ can be obtained simply by lifting the patients' hands, without other movement.

CBCT hepatic arteriography, it's a technique involves a single CBCT acquisition with one contrast medium injection through a catheter or a micro catheter positioned in the common hepatic artery in case of the normal hepatic anatomy, in case of the any variant hepatic artery, the variant vessel will be catheterized and CBCT will be done from that vessel. Nonetheless, an acquisition delay after injection start of 2-10 seconds, and an injection rate of $2 \mathrm{~mL} / \mathrm{sec}$ of non-ionic iodinated contrast medium diluted to $150 \mathrm{mg} / \mathrm{ml}$ concentration $(50 \%)$ (Omnipaque 300, Mallinckrodt, St. Lois, Missori) were injected.

CBCT hepatic arteriography aim was to depict occult HCC lesions unseen on nonselective digital subtraction angiography images during trans arterial chemoembolization.

Optimal thick cross-sectional images were obtained for observation of CBCT images on a workstation (Siemens Medical Systems). The matrix size is $512 \times 512$, and the field of view (FOV) is $25 \mathrm{~cm}$. Maximum intensity projection (MIP) images from $\mathrm{CBCT}$ can also be used to observe the vascular anatomy.
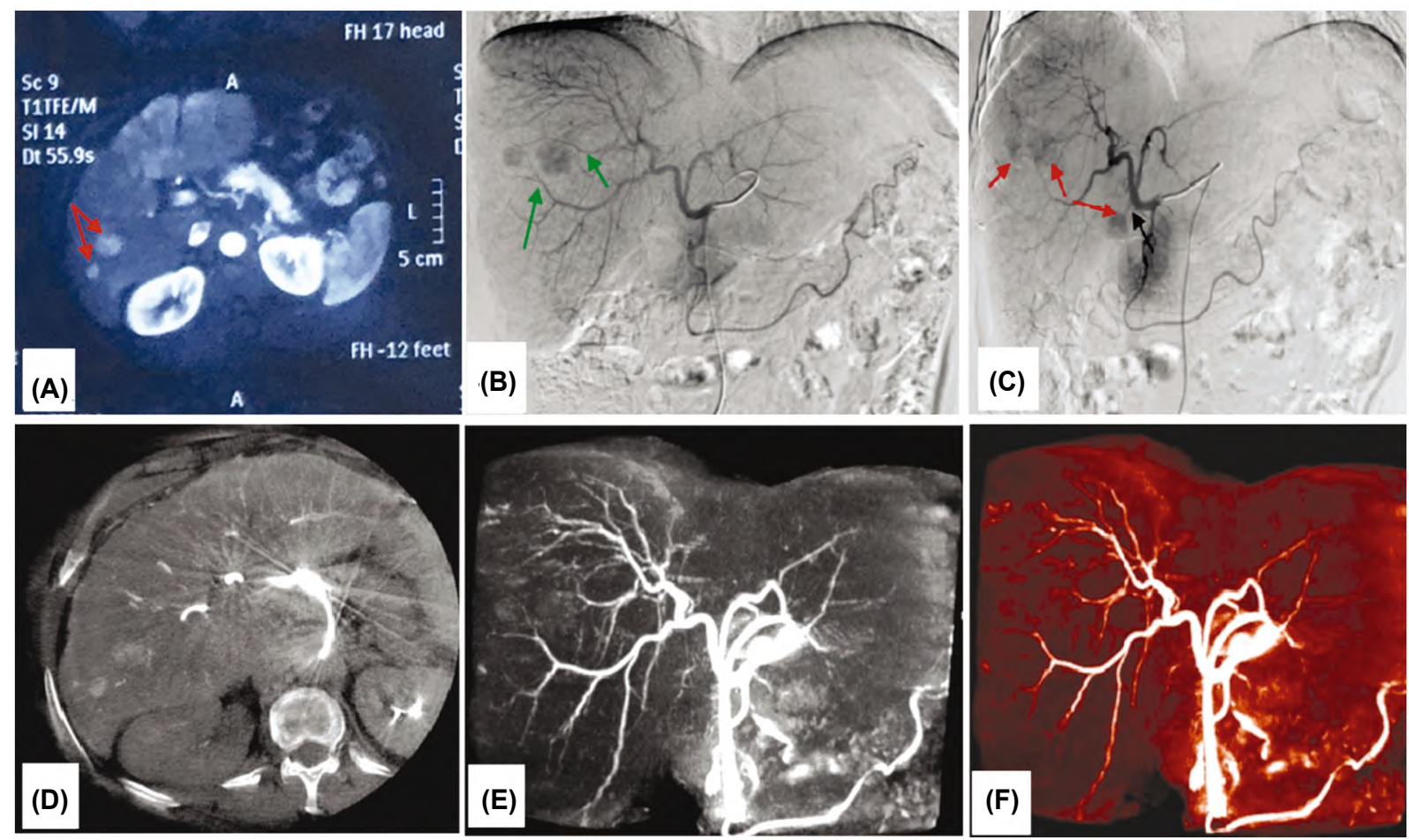

Fig. (1): A 56 years-old male patient with history of hepatitis $C$ positive and liver cirrhosis. (A): Pre-imaging MRI shows 2 lesions at segment VI. (B,C): DSA shows 3 lesions at segment VI, single feeding vessels for each tumor. (Red arrows for lesions, green arrows for feeder vessels). (D,E,F): CBCT 4 lesions at segment VI, one lesion at segment II, single feeding vessel for each tumor. (Red arrows for lesions, green arrows for feeder vessels). 

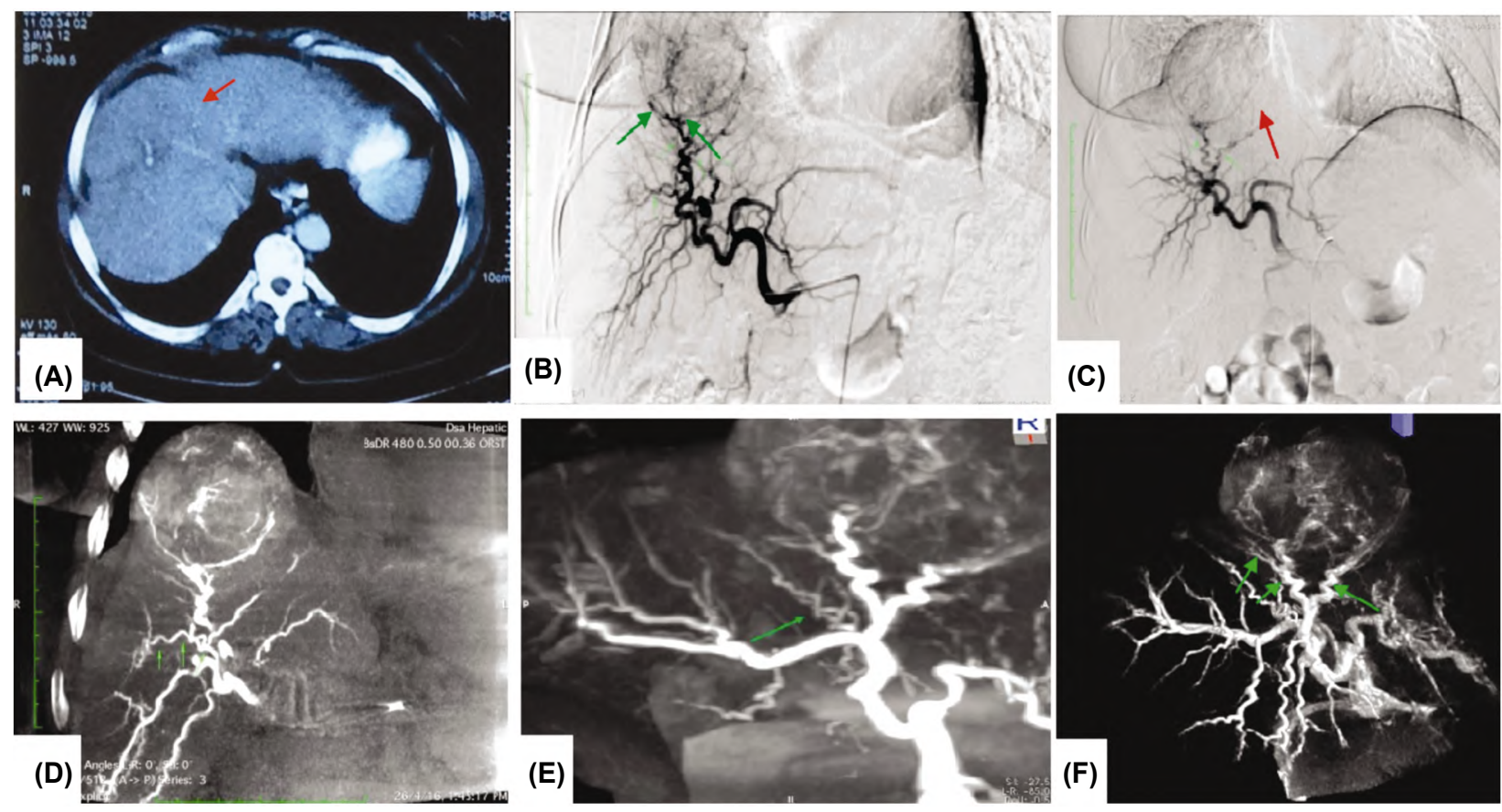

Fig. (2): A 57 years old female patient with history of hepatitis C positive and liver cirrhosis. (A): Pre-imaging CT: Lesion at segment VIII. (Red arrows for lesions). (B,C): DSA: Lesion at segment VIII with 2 tumor feeders. (Red arrows for lesions, green arrows for feeder vessels). (D,E,F): CBCT: Segment VIII lesion with 3 tumor feeding vessels and additional tumor at segment VII. (green arrows for feeders' vessels).
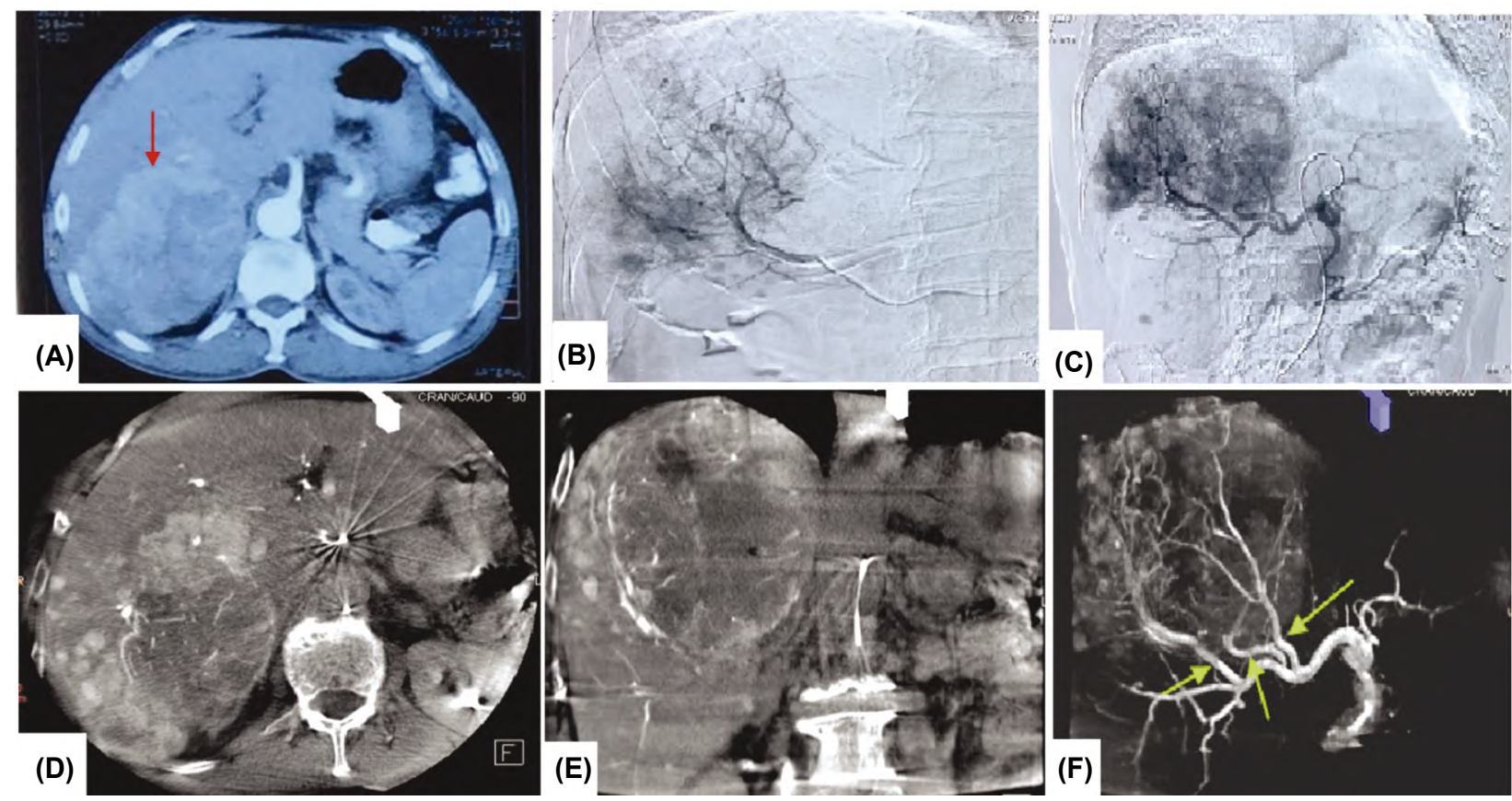

Fig. (3): A 65 years-old male patient with history of hepatitis $C$ positive and liver cirrhosis. (A): Pre-imaging CT: Large lesion at segment VII/VIII. (Red arrows for lesion). (B,C): DSA: multifocal lesions at right and left lobes, 3 tumor feeders for segment VII/VIII lesion, one feeder for each tumor. (D,E,F): CBCT: Multifocal lesions , 3 tumor feeders for segment VII/VIII, single feeder for each tumor.(green arrows for feeder vessels). 
Detection of tumor-feeding branches with syngo Dyna CT:

Syngo Dyna was used on a work station (Artis zee floor mounted system with Dyna CT; Siemens, Forchheim, Germany), When the target tumor had multiple feeder vessels. All raw data were transfered to the system software for reconstruction images. All processes were done for approximately 2-8 minutes after acquisition of CT HA images according to the number of tumors in each patient.

\section{Definition of tumor-feeding branches:}

We evaluated tumor-feeding branches at the subsegmental artery of the hepatic artery. A microcatheter was advanced into any branch that was suspected to be a tumor-feeding branch. Selective catheterization into the tumor-feeding branch was attempted under a postero-anterior fluoroscopic view with reference to 3D images with the feeding branches. If the orifice of the feeding branch was unclear, selective catheterization was attempted under the optimal oblique view determined by 3 D images.

The selected branch was determined as a tumorfeeding branch when partial or entire tumor staining was demonstrated on DSA and/or selective CT during HA, or when iodized oil accumulation in the tumor was demonstrated on $\mathrm{CT}$ with Lipiodol injection.

\section{Definition of technical success:}

Unenhanced CT was performed one month after chemoembolization in all patients to check the iodized oil distribution. According to these CT images, technical success was divided into three grades: complete, adequate, and incomplete.

Complete success was defined by iodized oil distribution including the entire tumor with at least a 5-mm-wide circumferential margin; an adequate embolization was defined by iodized oil distribution including the entire tumor, but without a uniform5$\mathrm{mm}$-wide safety marginal along all parts of the circumference; and incomplete embolization was defined by the area of iodized oil distribution not including the entire tumor.

\section{Results}

Assessment:

The detectability of the tumor with DSA obtained at the common, proper, right, or left hepatic artery (i.e., nonselective DSA) and cone-beam CT was compared.

Tumor stain and feeding branches were evaluated. The detectability of the tumor-feeding branch with non-selective DSA and Dyna CT analyzing the first CT HA images was compared.

A2 test was used to compare the detection rate of the tumors and tumor-feeding branches with non-selective DSA versus Dyna CT. With calculation of the $p$-Value of significance: $p$-value more than 0.05: non-significant and $p$-value less than 0.05: statistically significant. Statistical package used in statistical analysis was Statistical package for social science (SPSS 15.0.1 for windows: SPSS Inc. Chicago, IL. 2011).

Table (1): Demographic data of the studied cases.

\begin{tabular}{lll} 
& & No. $=25$ \\
\hline \multirow{2}{*}{ Age } & Mean \pm SD & $65.47 \pm 7.90$ \\
& Range & $55-80$ \\
\multirow{2}{*}{ Sex } & Female & $6(31.6 \%)$ \\
& Male & $13(68.4 \%)$ \\
\hline
\end{tabular}

Cone beam HA could sensitivity $(91.5 \%)$ specificity $(85.27 \%)$ while Nonselective DSA sensitivity $(73.1 \%)$ specificity $(98.8 \%)$.

Detectability of HCC with Cone-beam CT is demonstrated in (Table 2) that shows the predictive value of cone beam $\mathrm{CT}$ in different hepatic segments.

Table (2): Predictive value of cone beam CT in different hepatic segments.

\begin{tabular}{llllllllll}
\hline $\begin{array}{l}\text { Cone Sensi- } \\
\text { beam tivity }\end{array}$ & $\begin{array}{l}\text { Speci- } \\
\text { ficity }\end{array}$ & \multicolumn{2}{l}{ TP FN TN } & FP PPV & NPV & $\begin{array}{l}\text { Acc- } \\
\text { uracy }\end{array}$ \\
\hline I & $71.4 \%$ & $83 \%$ & 5 & 2 & 15 & 3 & $62.5 \%$ & $88.25 \%$ & $80 \%$ \\
II & $100 \%$ & $84 \%$ & 6 & 0 & 16 & 3 & $66.7 \%$ & $100.0 \%$ & $88 \%$ \\
III & $100 \%$ & $90 \%$ & 5 & 0 & 18 & 2 & $71 \%$ & $100.0 \%$ & $92 \%$ \\
IV & $100 \%$ & $83.3 \%$ & 7 & 0 & 15 & 3 & $70 \%$ & $100.0 \%$ & $88 \%$ \\
V & $62 \%$ & $94 \%$ & 5 & 3 & 16 & 1 & $83.3 \%$ & $84.2 \%$ & $84 \%$ \\
VI & $100 \%$ & $72.7 \%$ & 14 & 0 & 8 & 3 & $82.3 \%$ & $100.0 \%$ & $88 \%$ \\
VII & $100 \%$ & $87.5 \%$ & 9 & 0 & 14 & 2 & $81.8 \%$ & $100.0 \%$ & $92 \%$ \\
VIII & $93 \%$ & $80 \%$ & 14 & 1 & 8 & 2 & $87.5 \%$ & $88.9 \%$ & $88 \%$
\end{tabular}

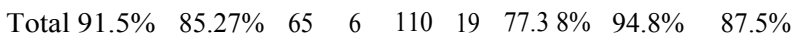

\section{Discussion}

The present study was undertaken to evaluate the role of the cone-beam CT that depict not only all tumors that were demonstrated on pre-procedural $\mathrm{CT}$ and MR imaging, but also additional tumors that were demonstrated during the chemoembolization procedure. The results of our study support earlier findings on CT hepatic arteriography [7] and provided essential information not available with DSA in $94.6 \%$ of chemoembolization in $82 \%$ of our patients, similar to that reported by Miyayama et al. [9] 
We evaluated whether CBCT provides the same information regarding hepatic tumor spread in patients with hypervascular tumors compared to MDCT. Both methods were used to assess the extent of hepatic tumor involvement before TACE. Regarding segmental tumor manifestation, a sensitivity ranging from $62 \%$ to $100 \%$ was obtained on CBCT; the specificity ranged from $73 \%$ to $90 \%$, this was comparable to sensitivity range from $97 \%$ to $100 \%$ was obtained on CBCT; the specificity ranged from $79 \%$ to $85 \%$ obtained by Bernhard et al., 2008 [10].

DSA is having high temporal resolution and in-plane spatial resolution but is lacking soft tissue contrast and 3D images [11]. On the other hand, CBCT has a smaller focal spot and larger matrix than multidetector CT (MDCT) resulting in higher spatial resolution [12]

Furthermore, hepatic arteries would be better depicted on CBCT images, because CBCT hepatic arteriography involves direct injection of contrast media in target vessels compared to MDCT scan- ning with peripheral injection. This is an important advantage when performing chemoembolization for HCC with CBCT hepatic arteriography because it enables the demonstration of subtle feeding arteries and provide a three-dimensional roadmap for microcatheter navigation to the target vessel or super-selective chemoembolization [13]

In the present study we used CBCT protocol (Artis zee floor mounted system with Dyna CT; Siemens, Forchheim,Germany), 321 projection images with 10.4-s acquisition with $207^{\circ}$ rotation of a $30 \times 38 \mathrm{~cm}$ FPD of the angiographic C-arm around the patient. Optimal thick cross-sectional images are obtained for observation of CBCT images on a workstation (Siemens Medical Systems). The matrix size is $512 \times 512$, and the field of view (FOV) is $25 \mathrm{~cm}$. Maximum intensity projection (MIP) images from CBCT can also be used to observe the vascular anatomy. In Table (3), Bapst B et al. [14] summarized use of CBCT for the detection of liver tumors during TAC in prior studies and in Table (4) we summarized our own technique and results in the same pattern.

Table (3): Studies reporting the use of CBCT for the detection of liver tumors during TACE.

\begin{tabular}{|c|c|c|c|c|c|c|c|c|c|}
\hline \multirow{2}{*}{ Study } & \multirow{2}{*}{$\begin{array}{l}\text { Tumor } \\
\text { type }\end{array}$} & \multirow{2}{*}{ No. } & \multirow{2}{*}{$\begin{array}{l}\text { TACE } \\
\text { tech. }\end{array}$} & \multirow{2}{*}{ Vendor } & \multicolumn{4}{|c|}{ Aquistion parameters } & \multirow{2}{*}{ Sensitivity } \\
\hline & & & & & Rotation(s) & Delay & $\begin{array}{c}\text { Volume } \\
\text { injected (mL) }\end{array}$ & $\begin{array}{l}\text { Injection } \\
\text { rate }\end{array}$ & \\
\hline \multirow[t]{2}{*}{ Hirota et al. } & \multirow[t]{2}{*}{$\mathrm{HCC}$} & \multirow[t]{2}{*}{4} & \multirow[t]{2}{*}{ cTACE } & \multirow[t]{2}{*}{ Hitachi } & 5 & $40 \mathrm{~s}$ & 46 & $2 \mathrm{~mL} / \mathrm{s}$ & \multirow[t]{2}{*}{$100 \% \mathbf{A}$} \\
\hline & & & & & 5 & $10 \mathrm{~s}$ & 20 & $1-2 \mathrm{~mL} / \mathrm{s}$ & \\
\hline \multirow[t]{2}{*}{ Meyer et al. } & \multirow[t]{2}{*}{$\mathrm{HCC}$} & \multirow[t]{2}{*}{2} & \multirow[t]{2}{*}{ cTACE } & \multirow[t]{2}{*}{ Siemens } & 10 & $3 \mathrm{~s}$ & 45 & $4 \mathrm{~mL} / \mathrm{s}$ & \multirow[t]{2}{*}{-} \\
\hline & & & & & 10 & $20 \mathrm{~s}$ & 40 & $4 \mathrm{~mL} / \mathrm{s}$ & \\
\hline \multirow[t]{2}{*}{ Meyer et al. } & $\mathrm{HCC}$ & 13 & \multirow{2}{*}{ cTACE } & \multirow{2}{*}{ Siemens } & 10 & & 40 & $3 \mathrm{~mL} / \mathrm{s}$ & \multirow[t]{2}{*}{$94 \% \mathbf{A}$} \\
\hline & Non-HCC & 17 & & & 10 & $2 \mathrm{~s}$ & 33 & $3 \mathrm{~mL} / \mathrm{s}$ & \\
\hline Miyayama et al. & $\mathrm{HCC}$ & 44 & cTACE & Philips & 20 & $20 \mathrm{~s}$ & 40 & $3 \mathrm{~mL} / \mathrm{s}$ & $89 \% \mathbf{B}$ \\
\hline \multirow[t]{2}{*}{ Miyayama et al. } & \multirow[t]{2}{*}{$\mathrm{HCC}$} & \multirow[t]{2}{*}{33} & \multirow[t]{2}{*}{ cTACE } & \multirow[t]{2}{*}{ Philips } & 10 & $25 \mathrm{~s}$ & 40 & $3 \mathrm{~mL} / \mathrm{s}$ & $94 \% \mathbf{A}$ \\
\hline & & & & & 10 & $7 \mathrm{~s}$ & 25 & $1.5 \mathrm{~mL} / \mathrm{s}$ & \multirow[t]{2}{*}{$97 \% \mathbf{A}$} \\
\hline Tognolini et al. & $\mathrm{HCC}$ & 84 & cTACE & Siemens & 8 & $4 \mathrm{~s}$ & 24 & $2 \mathrm{~mL}$ & \\
\hline Iwazawa et al. & $\mathrm{HCC}$ & 50 & cTACE & GE & 10 & $7 \mathrm{~s}$ & $9-36$ & $3-12 \mathrm{~mL} / \mathrm{s}$ & $86 \% \mathrm{C}$ \\
\hline Miyayama et al. & $\mathrm{HCC}$ & 71 & cTACE & Philips & 10 & $25 \mathrm{~s}$ & 40 & $3 \mathrm{~mL} / \mathrm{s}$ & $89 \% \mathbf{A}^{-} \mathbf{D}$ \\
\hline & & & & & & $7 \mathrm{~s}$ & $30-40$ & $1.5-2 \mathrm{~mL} / \mathrm{s}$ & \\
\hline Lin et al. & $\mathrm{HCC}$ & 3 & cTACE/DEB & Philips & 10 & $3 \mathrm{~s}$ & 20 & $2 \mathrm{~mL} / \mathrm{s}$ & - \\
\hline & & & & & 10 & $28 \mathrm{~s}$ & 20 & $2 \mathrm{~mL} / \mathrm{s}$ & \\
\hline Higashihara et al. & $\mathrm{HCC}$ & 30 & cTACE & Philips & 10 & $40 \mathrm{~s}$ & 90 & $2 \mathrm{~mL} / \mathrm{s}$ & $60 \% \mathrm{~A}^{-} \mathrm{C}$ \\
\hline Loffroy et al. & $\mathrm{HCC}$ & 20 & cTACE/DEB & Philips & 10 & $3 \mathrm{~s}$ & 20 & $2 \mathrm{~m} / \mathrm{s}$ & $94 \% \mathbf{D}$ \\
\hline & & & & & 10 & $28 \mathrm{~s}$ & & & \\
\hline Koelblinger et al. & $\mathrm{HCC}$ & 29 & cTACE & Siemens & 8 & $4-12 s$ & $48-80$ & $4 \mathrm{~mL} / \mathrm{s}$ & \\
\hline Tacher et al. & $\mathrm{HCC}$ & 19 & cTACE/DEB & Philips & 5 & $3 \mathrm{~s}$ & 20 & $2 \mathrm{~m} / \mathrm{s}$ & $94 \% \mathbf{D}$ \\
\hline & & & & & 5 & $28 \mathrm{~s}$ & & & \\
\hline Miyayama et al. & $\mathrm{HCC}$ & 68 & cTACE & Philips & 5 & $7 \mathrm{~s}$ & 24 & $2 \mathrm{~mL} / \mathrm{s}$ & $97 \% \mathbf{A}-\mathbf{D}$ \\
\hline & & & & & 5 & $25 \mathrm{~s}$ & 40 & $3 \mathrm{~mL} / \mathrm{s}$ & \\
\hline & & & & & 5 & $42 \mathrm{~s}$ & 24 & $2 \mathrm{~mL} / \mathrm{s}$ & \\
\hline Schernthaner et al. & ICC & 61 & cTACE & Philips & 5 & $3 \mathrm{~s}$ & 20 & $2 \mathrm{~m} / \mathrm{s}$ & $93 \% \mathbf{D}$ \\
\hline & & & & & 5 & $28 \mathrm{~s}$ & & & \\
\hline Paul et al. & Various & 150 & cTACE & Siemens & 8 & $6-9 \mathrm{~s}$ & 27 & $3 \mathrm{~mL} / \mathrm{s}$ & \\
\hline Lee et al & $\mathrm{HCC}$ & 142 & cTACE & Siemens & 8 & $4-6 s$ & $18-72$ & $1.5-6 \mathrm{~mL} / \mathrm{s}$ & $88-100 \% \mathbf{A}$ \\
\hline
\end{tabular}

Reference for sentivity: (A): Multidetector CT, (B): CT during arterial portography, (C): Lipiodol accumulation, (D): Contrast-enhanced MRI. $\begin{array}{lll}\text { ICC :Intrahepatic cholangiocarcinoma. } & \text { TACE :Transarterial chemoembolization. } & \text { (1): Transarterial chemoembolization. } \\ \text { HCC :Hepatocellular carcinoma. } & \text { CTACE :Conventional. } & \text { DEB : Drug-eluting beads. }\end{array}$ 
Table (4): Current study about the use of CBCT for the detection of liver tumors during TACE.

\begin{tabular}{|c|c|c|c|c|c|c|c|c|}
\hline \multirow{2}{*}{$\begin{array}{l}\text { Tumor } \\
\text { type }\end{array}$} & \multirow{2}{*}{ No. } & \multirow{2}{*}{$\begin{array}{l}\text { TACE } \\
\text { tech. }\end{array}$} & \multirow{2}{*}{ Vendor } & \multicolumn{4}{|c|}{ Aquistion parameters } & \multirow{2}{*}{ Sensitivity } \\
\hline & & & & Rotation(s) & Delay & $\begin{array}{c}\text { Volume } \\
\text { injected }(\mathrm{mL})\end{array}$ & $\begin{array}{l}\text { Injection } \\
\text { rate }\end{array}$ & \\
\hline $\mathrm{HCC}$ & 25 & cTACE & Siemens & 8 & $2-10 \mathrm{~s}$ & 50 & $2 \mathrm{~mL} / \mathrm{s}$ & $91.5 \%$ \\
\hline
\end{tabular}

Despite of its advantages, CBCT is having caveats like potentially increased radiation dose, contrast medium volume, and procedural time and the need for patient cooperation for a longer breathhold. Although, the radiation dose delivered during a single $\mathrm{C}$-arm $\mathrm{CT}$ acquisition is greater than that delivered during a single DSA acquisition yet, the skin dose of CBCT is distributed over $200^{\circ}$ because of the rotational nature of the acquisition Besides, single CBCT can yield the same information as multiple DSA acquisitions in technically challenging cases. CBCT, when performed in addition to standard DSA, adds to the total volume of contrast medium administered. However, as is true with radiation dose arguments, a single $\mathrm{C}$-arm CT may be equal or more informative than multiple DSA acquisitions. In addition, the contrast agent used for $\mathrm{CB}$ CT is diluted to $50 \%$ concentration to reduce streak artifact $[11,15,16]$

Technical aspects of transcatheter arterial chemo-embolization may have impact survival [17]. Analyzing the survival rates of patients with HCC (less than $7 \mathrm{~cm}$, fewer than 5 lesions) managed by chemoembolization. Yamakado K et al. [17] reported that survival rates of the selective chemoembolization group (i.e., at segmental artery or more distal level) were significantly higher than those of the non-selective chemoembolization group (i.e., chemoembolization at lobar or proper hepatic artery; $p=.0034)$. Iwazawa et al. [18] reported that patients treated with cone-beam CT-assisted chemoembolization had significantly higher overall $(p=0.005)$ and local progression-free $(p=0.003)$ survival rates than those who received chemoembolization with DSA alone.

Ultraselective transcatheter arterial chemoembolization has a strong therapeutic effect on small HCC lesions [7]. With advancement of imaging modalities, such as multi- detector-row helical CT scanners and MR imaging systems, smaller HCC lesions can be discovered. However, in such tumors, identification of the tumor-feeding branch on DSA, as well as tumor staining, is more difficult because the tumors are usually less hypervascular [7]

\section{Conclusion:}

Tumor detectability on cone-beam CT was significantly greater than on non-selective. Cone beam HA could identify more tumor-feeding branches at the level of the sub segmental artery of the hepatic artery in HCC lesions. We believe the technical success rates of ultraselective transcatheter arterial chemoembolization may be improved by chemoembolization guidance software that uses cone-beam CT technology.

\section{References}

1- LEONI S., PISCAGLIA F., GOLFIERI R., et al.: The impact of vascular and nonvascular findings on the noninvasive diagnosis of small hepatocellular carcinoma based on the EASL and AASLD criteria. The American Journal of Gastroenterology, 105 (3): 599-600, 2010.

2- PARENTE D.B., PEREZ R.M., EIRAS-ARAUJO A., et al.: MR Imaging of Hyper-Vascular Lesions in the Cirrhotic Liver: A Diagnostic Dilemma Radio Graphics, 32: $767-$ 787,2014

3- DESCHAMPS F., SOLOMON S.B., THORNTON R.H., et al.: Computed analysis of three dimensional cone beam computed tomography angiography for determination of tumor feeding vessels during chemoembolization of liver tumor: A pilot study. Cardiovasc. Intervent Radiol., 33 (6): 1235-1242, 2010.

4- BRUIX J. and SHERMAN M.: Management of hepatocellular carcinoma. Hepatology, 42 (5): 1208-1236, 2005.

5- TAMASKA P., RASKI G., PATAKI A. and LAZAR: The role of cone-beam CT during transarterial chemoembolization for liver cancer. Sep., 70 (3): 213-220. doi: 10.1556/1046.70.2017.3.1, 2017.

6- TACHER V., RADAELLI A. and GESCHWIND J.F How I do it: Cone-Beam CT during Transarterial Chemoembolization for Liver Radiology. February, 274 (2): 320-334, 2015.

7- HIGASHIHARA H., OSUGA K., ONISHI H., et al.: Diagnostic accuracy of C-arm CT during selective transcatheter angiography for hepatocellular carcinoma: Comparison with intravenous contrast-enhanced, biphasic, dynamic MDCT. Eur. Radiol., 22: 872-879, 2012.

8- SINEAD M.H., McCARTHY C.J., LAVELLE L.P., et al.: Hepatocellular carcinoma: Illustrated guide to systematic radiologic diagnosis and staging according to guidelines of the American Association for the Study of Liver Diseases. Radiographics, 33 (6): 1653-68, 2013.

9- MIYAYAMA S., YAMASHIRO M., OKUDA M., et al.: Usefulness of cone-beam computed tomography during ultraselective transcatheter arterial chemo-embolization for small hepatocellular carcinomas that cannot be demonstrated on angiography. Cardiovasc. Intervent Radiol., 32: 255-264, 2009 
10- BERNHARD C. MEYER, BERND B. FRERICKS, MAERTHE VOGES, et al.: Visualization of Hypervascular Liver Lesions During TACE: Comparison of Angiographic C-Arm CT and MDCT. American Journal of Roentgenology, 190: 4, W263-W269, 2008.

11- TOGNOLINI A., LOUIE J.D., HWANG G.L., et al.: Utility of C-arm CT in patients with hepatocellular carcinoma undergoing transhepatic arterial chemoembolization. Journal of Vascular and Interventional Radiology, 21 (3): 339-347, 2010.

12- KALENDER W.A. and KYRIAKOU Y.: Flat-detector computed tomography (FD-CT). Eur. Radiol., 17 (11): 2767-2779, 2007.

13- IWAZAWA J., OHUE S., MITANI T., et al.: Identifying feeding arteries during TACE of hepatic tumors: Comparison of C-arm CT and digital subtraction angiography. Am. J. Roentgenol., 192 (4): 1057-1063, 2009.

14- BAPST B., LAGADEC M., BREGUET R., VILGRAIN V. and RONOT M.: Cone Beam Computed Tomography
(CBCT) in the Field of Interventional Oncology of the Liver. CardioVascular and Interventional Radiology, 39 (1): 8-20, 2016.

15- SZE D.Y., RAZAVI M.K., SO S.K., et al.: Impact of multidetector CT hepatic arteriography on the planning of chemoembolization treatment of hepatocellular carcinoma. Am. J. Roentgenol., 177: 1339-1345, 2001.

16- WALLACE M.J., MURTHY R., KAMAT P.P., et al.: Impact of C-arm CT on hepatic arterial interventions for hepatic malignancies. J. Vasc. Interv. Radiol., 18: 15001507, 2007.

17- YAMAKADO K., MIYAYAMA S., HIROTA S., et al.: Hepatic arterial embolization for unresectable hepatocellular carcinomas: Do technical factors affect prognosis? Jpn. J. Radiol., 30: 560-566, 2012.

18- IWAZAWA J., OHUE S., HASHIMOTO N., et al.: Survival after C-arm CT-assisted chemoembolization of unresectable hepatocel-lular carcinoma. Eur. J. Radiol., 81: 3985-3992, 2012.

\section{دور الأثعة المقطعية ذات الشعاع المخروطى فى تحسين فرصية

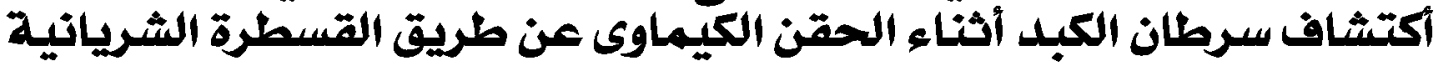

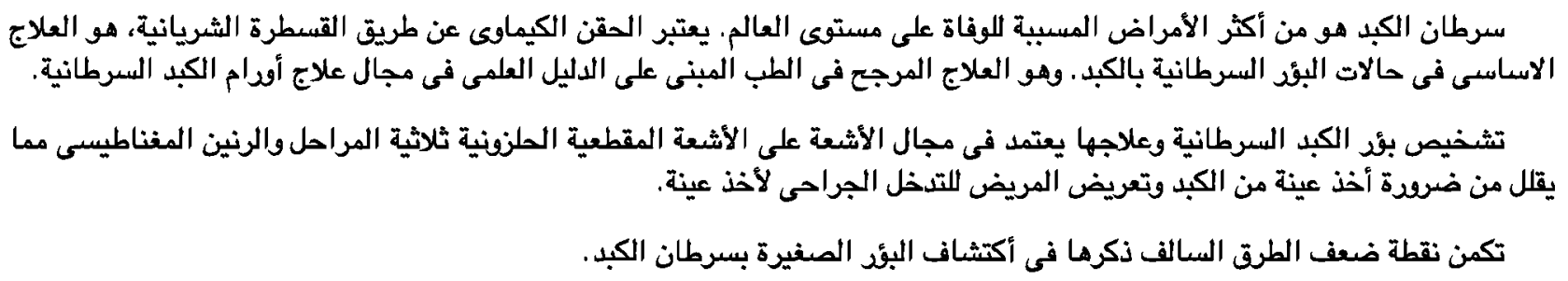

ولذلك أن استخدام الأثعة المقطعية ذات الشعاع المخروطى أثبت علمياً أنه أكثر حساسية ودقة عن الأشعة المقطعية الحلزونية ثلاثية

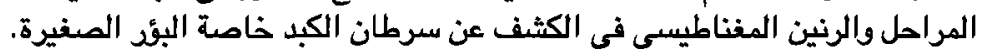

